\title{
Tuberculosis infection and disease among schoolchildren: the influence of the HIV epidemic and of other factors
}

\author{
J R Villalbí, H Galdós-Tangüís, J A Caylà, P Casañas, A Ferrer, M Nebot
}

\begin{abstract}
Background-The HIVIAIDS epidemic has caused an excess of tuberculosis cases in Spain and in other countries, but its impact on tuberculosis infection is less well understood. This study presents a massive screening undertaken to estimate the prevalence of tuberculous infection in a cohort of primary school entrants. The evolution of the risk of infection is studied by comparison with previous data in the same population.

Methods-Tuberculin skin test screening with 2TU of PPD RT 23 of first grade students in the primary schools of Barcelona, in the 1994-95 school year (cohort born in 1988). Information was also sought from families of unscreened children. Contacts of PPD+ children were traced to locate index cases. The results were also linked to the case registry of the tuberculosis control programme.
\end{abstract}

Results-The prevalence of tuberculin reactors free of BCG vaccination among the 11080 schoolchildren screened belonging to the 1988 cohort was $0.76 \%$. A 3\% annual decline in the annual risk of infection is estimated by comparison with previous data. The identification of 24 cases with a previous history of tuberculosis disease and of 13 cases with active disease diagnosed after the screening was possible by the follow up of these tuberculin positive children and of the information provided by families of unscreened pupils. The screening detected 1.5 new cases of tuberculosis per 1000 tuberculin tests performed. Tuberculosis infection could be traced to HIV infected tuberculosis cases for at least $6 \%$ of the positive schoolchildren.

Conclusions-The decline of the annual risk of infection continues in Barcelona, although at a slower pace than before the HIVIAIDS epidemic, probably attributable to the influence of injecting drug users with smear positive tuberculosis and HIVIAIDS.

(F Epidemiol Community Health 1999;53:112-117)

The human immunodeficiency virus (HIV) infection has caused a clear excess of tuberculosis cases in Spain and in other countries. ${ }^{12}$ The evolution of tuberculosis infection is less well understood. Some authors believe that the decline in infection continues, as the excess cases linked to the HIV epidemic is caused by the expression of tuberculosis disease among people who were already infected by Mycobacterium tuberculosis years ago, among whom the acquired immunodeficiency explains the clinical disease. ${ }^{34}$ However, a proportion of these cases may be infective, and thus contribute to the dissemination of infection to new population groups. In Spain, the concentration of HIV infection among people who are injecting drug users, ${ }^{56}$ many of whom are relatively young and are household contacts of children, could promote this infection pathway. In this context, monitoring the evolution of infection and disease becomes crucial to understand current changes. This is why this study was undertaken, based on the tuberculin screening of schoolchildren in the months of January to May 1995, during the first year of mandatory schooling (first grade, when pupils are 6-7 years old).

Universal BCG vaccination was interrupted in Catalonia and in Barcelona from 1976, so that current schoolchildren are free of BCG interference when submitted to the tuberculin test, except for a few born in other areas where BCG is used. Universal screening in first grade was interrupted in Barcelona in 1989 as less than $1 \%$ of the children tested were positive. ${ }^{7} \mathrm{~A}$ first grade screening policy was kept for schools located in neighbourhoods considered to be at higher risk because of social and health criteria. To monitor the evolution of infection, universal screening of first graders was done in 1992. Its results suggested that infection prevalence kept declining, but at a slower pace than previously estimated. $^{8}$ The comparison with previous studies was obscured by changes in tuberculin supply, as the Comité d'Experts en Tuberculosi (Catalan Expert Committee on Tuberculosis) recommended in 1989 the use of 2 TU of PPD RT 23 instead of the 5 TU previously used. ${ }^{9}$ This paper reports the results of a second universal screening with 2 TU of PPD RT 23, performed three years later, whose objectives are to assess the evolution of tuberculosis infection, and to clarify the status of those children not tested because parents explicitly denied permission for the test. The contribution of school-based screening to the identification and control of sources of infection is also evaluated, after a tuberculosis control programme has been in operation for 10 years.

\section{Methods}

Tuberculin skin tests were performed with 2 TU of PPD RT-23, in $0.1 \mathrm{ml}$ of liquid solution and stabilised with Tween 80, in accordance 
Table 1 Prevalence of tuberculin reactors according to the screening in the 1988 cohort by school district. Barcelona, 1994-95

\begin{tabular}{lccl}
\hline District & $P P D+$ & Schoolchildren screened & Prevalence (\%) \\
\hline Ciutat Vella & 10 & 469 & 2.13 \\
Eixample & 12 & 1461 & 0.82 \\
Sants & 7 & 1026 & 0.68 \\
Les Corts & 1 & 714 & 0.14 \\
Sarria-Sant Gervasi & 12 & 2037 & 0.59 \\
Gracia & 7 & 734 & 0.95 \\
Horta-Guinardo & 13 & 1348 & 0.96 \\
Nou Barris & 8 & 944 & 0.84 \\
Sant Andreu & 6 & 988 & 0.61 \\
Sant Marti & 8 & 1362 & 0.58 \\
Total Barcelona & 84 & 11074 & 0.76 \\
\hline
\end{tabular}

with the recommendations of the Departament de Sanitat i Seguretat Social (DSSS, the Health Department of the Catalan Government), and the National Consensus on Tuberculosis of Spain. ${ }^{910}$ As in the 1991-92 survey, tests were performed according to Mantoux procedure by nurses from the municipal school health teams, who had been previously trained to reach standardisation in skin test placement and reading, and who had wide experience in this task. Readings were made 72 hours after injection, and a test was considered to be positive when an induration with a diameter of $5 \mathrm{~mm}$ or more was measured, following the current guidelines, defined according to the low prevalence of atypical mycobacteria in Barcelona. ${ }^{9-12}$

Families of first grade pupils were informed before the test administration, and information was sought on previous tuberculin tests, as well as on place of birth and BCG vaccination, for those children not born in Catalonia. Rosters of all first graders, including date and place of birth, were kept. Children with a positive test were referred to the clinics of the Tuberculosis Prevention and Control Program of the DSSS. Those children testing positive who failed to attend the clinic were followed up to ascertain the causes. Thus, PPD+ children were classified according to the reason for testing positive: current or former cases of tuberculosis, infected without tuberculous disease, or BCG reactors free of tuberculosis. The nominal register of cases managed by the Division of Epidemiology of the Municipal Institute of Health was linked with the list of PPD+ children, to find out the cases of tuberculosis in the 1988 cohort who had been reported before the screening. ${ }^{13}$

Most schoolchildren screened were six years old at the time of the screening, but some were seven or even older. In fact, according to the existing regulations, children beginning first grade in 1994-95 are those children born in 1988, who must be six years old in 1995. As the screening was undertaken between January and May 1995, some of them were already seven years old when tested. Because some repeatees are included in first grade, only data from the 1988 birth cohort are included. Annual risk of infection (ARI) is estimated by $1-(1-\mathrm{P})^{1 / \text { age }}{ }^{14}{ }^{15}$ Results are shown by school district, and compared with information available from previous years. The $\chi^{2}$ test was used to compare proportions.

\section{Results}

The screening was offered to all schools in the city, and 379 schools, with $99.7 \%$ of all first graders, participated. In the 1988 cohort, 11200 tests were made, and 11080 read, with 90 testing positive. All were referred to the Tuberculosis Prevention and Control Program Clinics, where six of them, who were found to have been born outside Catalonia and to be BCG vaccine recipients were eventually considered to be vaccine reactors free of tuberculosis. Thus, there were 84 positive tests, with an

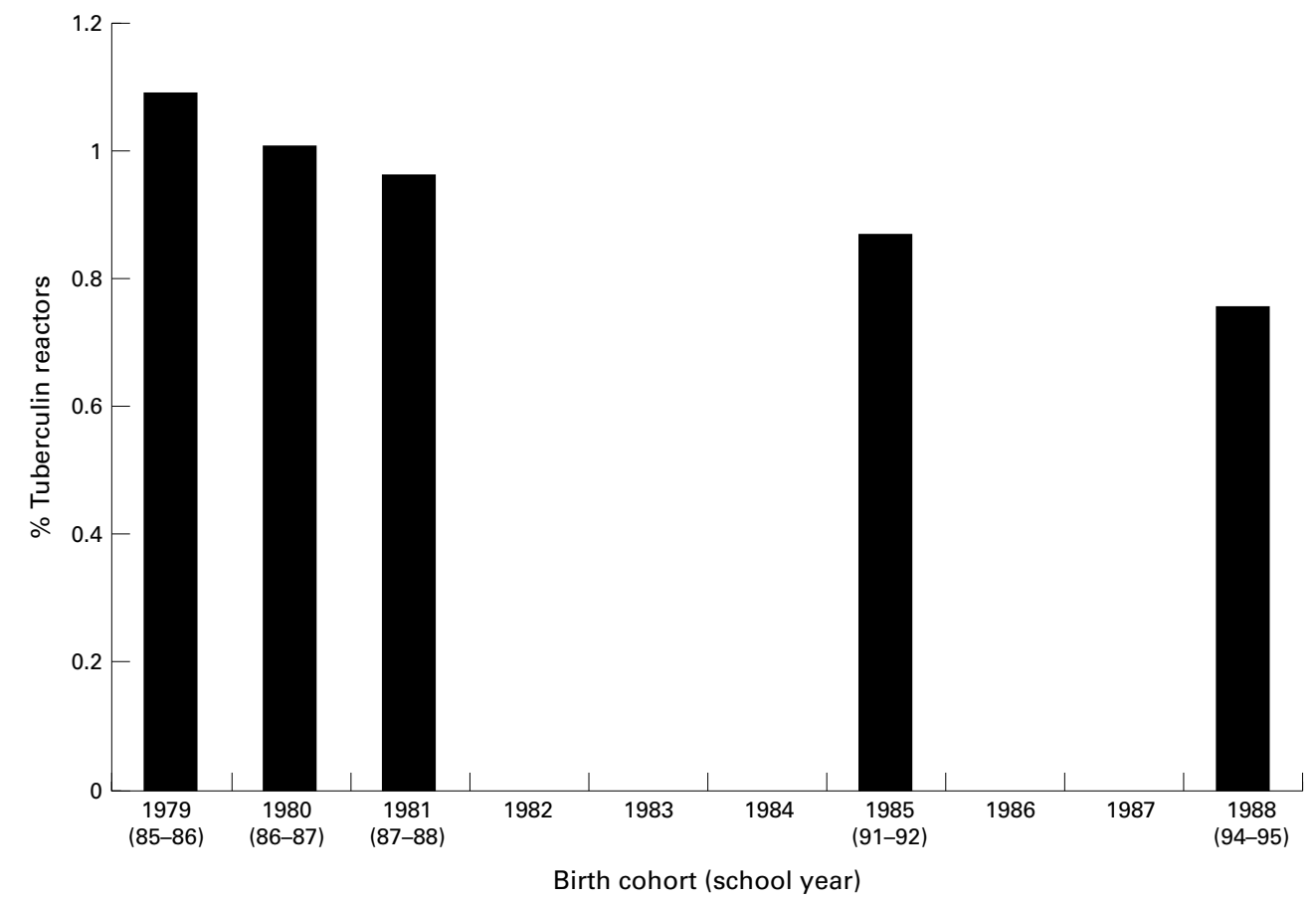

Figure 1 Proportion of tuberculin reactors among first grade schoolchildren by birth cohort. Barcelona, 1985-86 to 1994-95. 


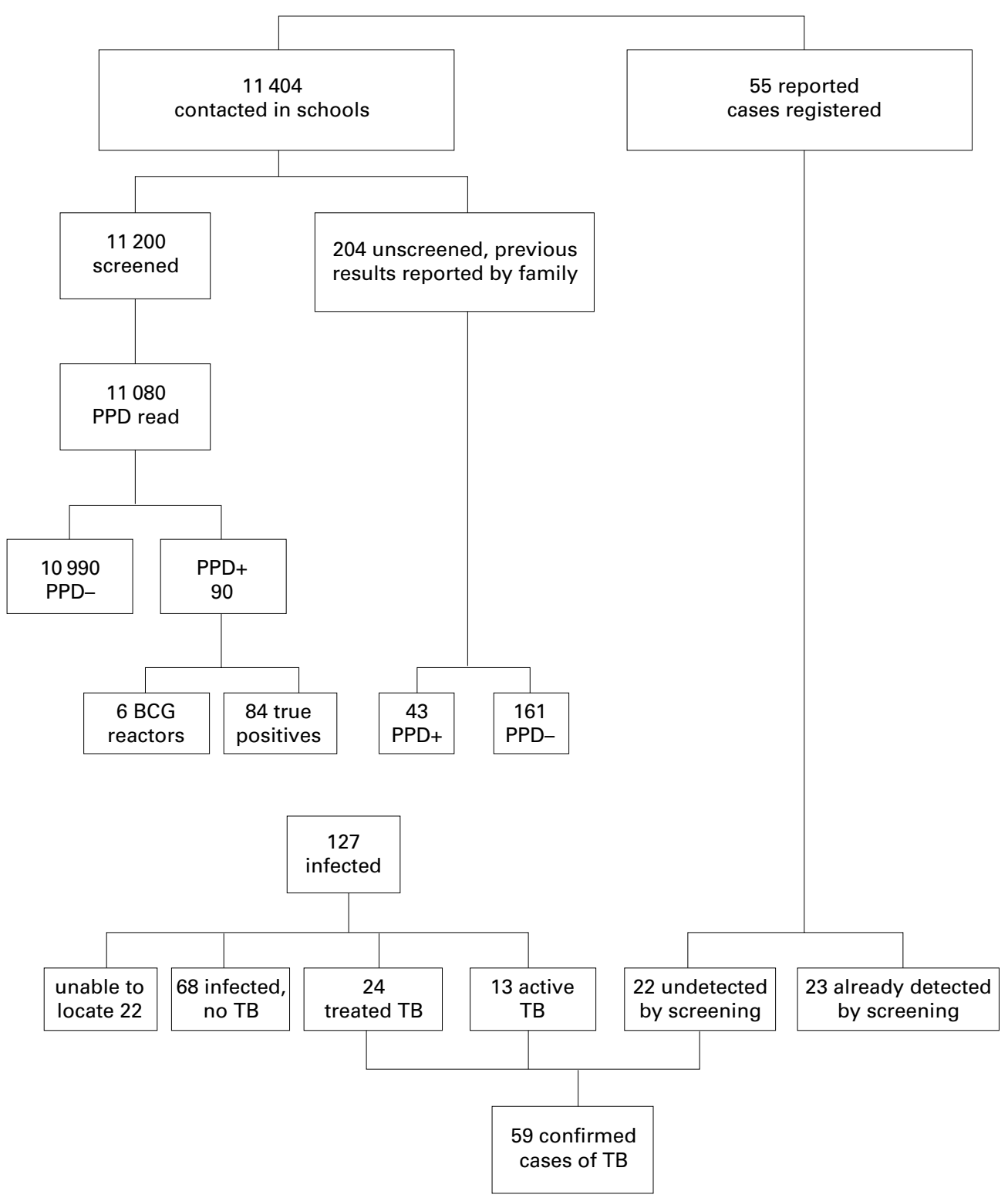

Figure 2 Survey results and reported tuberculosis cases in the 1988 cohort. Barcelona, 1994-95.

estimated prevalence of $0.76 \%$. The ARI estimate for $1994-95$ is $0.10 \%$. Table 1 presents the prevalence of PPD+ by school district. It fluctuates between $2.13 \%$ in the inner city Ciutat Vella district and $0.14 \%$ in Les Corts. Among the $10 \mathrm{PPD}+$ in Ciutat Vella, three were children from immigrant families from developing countries.

The results of tuberculin screenings in first grade, which were done with similar methods in the Barcelona schools over a decade, between 1985-86 (cohort born in 1979) and 1994-95 (cohort born in 1988) are shown in figure 1. However, until 1989-90 the DSSS supplied 5TU PPD RT-23, and 2TU PPD RT-23 was supplied afterwards. The annual mean decline of the ARI is 3\% by comparison of the 1994-95 estimate with the previous estimate of $0.12 \%$ in $1991-92$.

In this survey, systematic information on previous tests was sought from families. The families of 204 children whose parents denied consent for PPD testing, provided written information, and a positive result was reported for 43. If these data are combined with the screening results, the frequency of infection would be 127 among the 11404 first graders for whom some information is available $(1.11 \%)$. Then the ARI would be estimated at 0.16 , a figure that is not comparable to previous data, which were derived from the results of the direct reading of PPD tests.

The follow up of the 127 PPD+ (84 found by screening and 43 reported by families, but not screened) confirmed the presence of 68 children with infection but free from tuberculous disease, 24 children with a previous history of tuberculosis, and of 13 cases of active disease diagnosed after the screening. Despite several attempts, the families of 22 children with a positive test could not be located for follow up. Through the linkage of this information with the nominal case registry, it was found that among the 24 children with a history of tuberculosis, 23 had been already reported to the case registry $(95.8 \%$ completeness in 
reporting). The non-reported case had been diagnosed in a private centre and treated with an appropriate course of therapy. The nominal case registry had information on 22 more children from the 1988 birth cohort with a history of tuberculosis, so the total number of children with a history of disease may increase to 59, and the number of infected children to 149 . Figure 2 summarises the combination of survey data and registry information.

The source of infection was found for 42 children, 33 of the 59 children with tuberculosis disease $(55.9 \%)$, and 9 of the 68 children who were infected but disease free $(13.2 \%)$ $(p<0.001)$. Four index cases were detected through the screening, while 38 were already known. Among the 33 first grade cases whose source of infection could be found, six were related with HIV infected patients. Four cases among first graders were related to a single index case, a smear positive and HIV- teacher, infected by a smear positive and HIV+ brother with a history of intravenous drug use. Thus, six children with the disease may be traced to smear positive HIV+ cases, all of them with a history of intravenous drug use $(18.2 \%$ of the 33 children whose contacts could be studied, and $10.2 \%$ of the 59 children with the disease). Among the 149 children who had either been cases of tuberculosis or only infected with $M$ tuberculosis, a source of infection related to HIV could be found for nine $(6 \%)$.

The screening of 11080 first graders resulted in the finding of 13 new cases among children, and four new cases among adults, who were index cases. Thus the yield of the screening was the detection and treatment of 1.5 previously unknown cases per 1000 tests (besides the chemoprophylaxis among children infected and free of disease).

\section{Discussion}

The comparability of these results with those of previous surveys may be considered. As the city population is rather stable, the proportion of unscreened children is similar in different surveys: in 1988 there were 13556 births from city residents, and in 1994-95 there were 11080 tests among this cohort $(81.7 \%)$; in the 1991-92 survey, 12007 tests were done in the 1985 cohort, which had numbered 15190 births $(79 \%)$. The reporting of previous tuberculin tests by families does not decrease screening coverage. On the contrary, it provides information on a fraction of the unscreened children, which sheds new light on those not covered by the screening, suggesting that many of them have been in contact with $M$ tuberculosis. Although the accuracy of parental reporting has not been ascertained, this finding is relevant for the interpretation of screening surveys, and points to the small unscreened fraction as crucial in the understanding of the results. Although any estimate of the current situation must take into account the information reported by families, to maintain the internal validity of infection decline estimates, only data derived from the PPD tests actually performed during the survey should be used, to preserve comparability, as information reported by families on unscreened children was not available for previous surveys.

The comparison of these results with those of other studies in Spain raises methodological issues. In recent years, screenings using similar methods have been conducted in the Region of Murcia, and the estimated prevalence has been slightly lower than in Barcelona, which is understandable as infection prevalence is higher in the pockets of marginality found in large cities. ${ }^{16}{ }^{17}$ The comparison of these results with those in the Region of Madrid would be most interesting: a recent survey in Madrid found $0.3 \%$ of PPD+. ${ }^{18}$ Unfortunately, the comparison is not appropriate, because the sampling method in the Madrid Region (a stratified sampling with three strata and a sampling fraction of $4.4 \%$ ) is very likely to underestimate prevalence for a low frequency event with a frequently aggregate occurrence such as tuberculosis infection. In Barcelona, if the three schools with more than two positive tests (all of which were in the inner city) had not been screened, the estimated prevalence would have been $12 \%$ lower. The probability that one of these schools would be included in a sample such as in the Madrid screening is lower than 0.02. Besides, there is no information for unscreened children in Madrid. Thus, comparisons with the Madrid Region prevalence should not be undertaken.

The 22 reported cases in the nominal case registry that were not found by the screening, point to the fact that the unscreened children differ from the screened. Although some of these children may belong to families who have moved from the city, most probably they were either absent from schools on screening days, or their families refused the tuberculin test and did not report the history. Perhaps they fear negative social reactions in the school setting because of tuberculosis. If we accept these cases as city residents and add them to the screening results, we could estimate 59 cases over the first seven years of age for the 13556 children born in 1988: an annual incidence rate of 62.2 cases per 100000 person years, which seems rather high for our social context. These figures may be overestimates because of two reasons. In the first place, because they include selective information from unscreened subjects who enter the denominator only because they enter the numerator. In the second place, because some PPD+ may be false positives because of atypical mycobacteria. They are likely to be among those PPD+ for whom no index case was found. We have found more index cases among contacts of cases than among contacts of PPD+, although it may be that the contact tracing effort is more intense for a clinical disease case than for a positive tuberculin test. If close contact with a smear positive case is more likely to result in tuberculosis disease than in just infection, contact tracing is more likely to identify sources of infection that resulted in new cases. The studies on atypical mycobacteria conducted in Barcelona 15 years ago, ${ }^{11}{ }^{12}$ which established a low prevalence of atypical mycobacteria, should be 
repeated, as its ecology may have changed in the meantime.

As this study shows, it is difficult to have an accurate estimate of infection prevalence in a community. For most populations, comprehensive data linking cross sectional surveys and case registries are not available. The $1.32 \%$ prevalence, estimated by combining survey data and the registry information, almost doubles the $0.76 \%$ prevalence estimated from the direct PPD test results. It reflects the current situation in the city, where a comprehensive control programme has now been in operation for 10 years, and questions survey results from areas without a surveillance programme and that ignore the unscreened population. Recently, studies based on active surveillance methods have estimated incidence rates similar or higher than in Barcelona for other areas in Spain for which case rates previously derived from routine reporting were low. ${ }^{19} 20$

These results strongly suggest that the decline of tuberculosis infection in the city of Barcelona continues, although at a slower pace than estimated before the HIV epidemic. ${ }^{7}$ Thus, despite the relatively high AIDS incidence rates and the associated increase in reported cases of tuberculosis from 1989 to $1991,{ }^{13}$ tuberculosis infection among children has not increased. This conclusion is relevant for Barcelona, for Spain, and for other countries with a similar epidemiological pattern. The change from $5 \mathrm{TU}$ to $2 \mathrm{TU}$ in the PPD test made the comparison of the 1992 survey results with previous surveys problematic, but now this conclusion may be reached despite some limitations of this study, as both the 1992 and 1995 surveys have been based in 2TU. In fact, we may have overestimated the ARI because of the increasing number of children from families immigrating from developing countries, as their rates of infection may reflect the risk in their country of origin rather than the risk in the city. ${ }^{21-23}$ While some are born in Spain, others were born in other countries and immigrated later on: in the early $90 \mathrm{~s}$, about $2 \%$ of all live births are to mothers born in a developing country. It is hard to disentangle their influence in more depth. Analysis by place of birth or guessing ethnicity from children's names have limited validity, and the routine collection of information on race or ethnicity in vital and census statistics is currently not considered acceptable in Spain.

The screening was undertaken to better understand the current epidemiology of tuberculosis infection. However, it has also resulted in the early detection of both cases and infected schoolchildren from the 1988 cohort, and thus chemotherapies and chemoprophylaxis should decrease the risk of disease incidence in this cohort. Because of this screening, several index cases previously unknown have been detected. Its yield is higher in our context than in other settings, ${ }^{24}$ and it should not be overlooked, especially in deprived areas. This strategy was already being used in those neighbourhoods considered to be at higher risk, and this should result in a decrease in the future disease incidence among the screened cohorts. In fact,
KEY POINTS

- Tuberculosis infection among children keeps declining in an urban population with an organised tuberculosis control programme despite the resurgence of tuberculosis reports associated with the HIV/AIDS epidemic.

- When conducting a large scale tuberculin survey in schools, attention should be paid to the fact that many children with a history of tuberculosis or with a previously known infection are likely to be among the non-participants.

- In one of the urban areas with higher AIDS incidence in southern Europe, tuberculosis infection could be traced to $\mathrm{HIV}$ infected tuberculosis cases for at least $6 \%$ of PPD+ children.

there has been a decrease in the rates among children and teenagers in Barcelona over the past years, while incidence rates in young adults increased.

We may infer from these results that a smear positive and HIV infected patient was the source of infection for at least $6 \%$ of all children with infection. This confirms the potential of the tuberculosis-HIV coinfection to influence the epidemiology of tuberculosis. However, this figure must be put in context: according to the Barcelona case registry, 28\% of all new tuberculosis cases are infected by the HIV. ${ }^{13}$ The epidemiology of HIV in Barcelona shows that it is strongly related to intravenous drug use, which is more frequent in the most deprived areas of the city: this has resulted in a high frequency of HIV infection in those population groups who already suffered traditionally from high rates of tuberculosis infection. The epidemiology of HIV/AIDS in Spain may be defined by this pattern: some population segments with historically high rates of tuberculosis infection have also suffered heavily from HIV infection. This has resulted in higher rates of tuberculosis disease because of the immunity suppression caused by HIV, and also in high rates of AIDS, because of the impact of tuberculosis as an AIDS indicator disease. This pattern may also be true in other countries of southern Europe: high AIDS incidence rates linked to intravenous drug use and relatively high tuberculosis infection rates in childhood until two decades ago, result in high coinfection for young adults, especially among some population groups.

Tuberculosis control must now face new challenges. The prevention of new infections remains the key issue: from a public health perspective, the main priority is still the early detection and proper treatment of tuberculosis cases, specially of smear positive cases. ${ }^{25} 26$

Funding: this study was partly financed by the Fondo de Investigaciones Sanitarias (Exp 96/1336).

The authors wish to express their recognition to the Dispensari de Prevenció i Control de la Tuberculosi del Departament de Sanitat i Seguretat Social de la Generalitat de Catalunya whose invaluable help made the study possible. They also wish to 
express their gratitude to the school health teams for their daily work and to the principals of the city schools for all their patience and support.

1 Rey R, Ausina V, Casal M, Caylà J, de March P, Moreno S, et al. Situación actual de la tuberculosis en España. Una et al. Situacion actual de la tuberculosis en España. Una perspectiva sanitaria en precario respecto a
desarrollados. Med Clin (Barc) 1995;105:703-7.

2 Brudney K, Dobkin J. Resurgent tuberculosis in New York City: human immunodeficiency virus, homelessness, and the decline of tuberculosis control programs. Am Rev Respir Dis 1991;144:745-9.

3 de March P, García A. La evolución de la infección VIH/sida en los países desarrollados. Impacto sobre la tuberculosis. Med Clin (Barc) 1993;100:187-93.

4 Styblo K. The potential impact of AIDS on the tuberculosis situation in developed and developing countries. Bulletin International Union Tuberculosis 1988;63 (suppl 2):25-8.

5 Caylà JA, Jansà JM, Iglesias B, Artazcoz L, Plasència A. Epidemiología del síndrome de inmunodeficiencia adquirida en Barcelona (1981-1991)(I). Estudio descriptivo y de
tendencias temporales. Med Clin (Barc) 1993;101:286-93.

6 Casabona J, Salas T, Segura A. Evolución de la epidemia de sida en Cataluña: análisis descriptivo del registro de casos. Med Clin (Barc) 1989;92:441-6.

7 Villalbí JR, Caylà JA, Taberner JL, Serra T. El declive de la infección tuberculosa en escolares de Barcelona. Med Clin infección tuberculosa en

8 Villalbí JR, Caylà JA, Iglesias B, Ferrer A, Casañas P. The evolution of tuberculosis infection among schoolchildren in Barcelona and the HIV epidemic. Tuber Lung Dis 1994;75: $105-9$

9 Comité d'Experts en Tuberculosi. Guia per a la prevenció $i$ control de la tuberculosi. Barcelona: Publicacions de la Generalitat de Catalunya, 1992.

10 Grupo de Trabajo sobre Tuberculosis. Consenso nacional para el control de la tuberculosis en España. Med Clin (Barc) 1992;98:24-31

11 Taberner JL. Sensibilidad cruzada entre tuberculina RT23 y sensitinas de micobacterias atípicas. Gac Sanit 1982;4:5-7.

12 de March-Ayuela P. Micobacterias no tuberculosas en Barcelona (I). Sensibilizaciones comparativas entre tuberculina RT23 con sensitinas del Mycobacterium avium y Scrofulaceum. Rev Clin Esp 1984;175:141-7.

13 Caylà JA, Galdós-Tangüis H, García de Olalla P, Brugal MT, Jansà JM, Miranda PSC. La tuberculosi a Barcelona.
Informe 1994. Barcelona: Publicacions de l'Ajuntament de Barcelona, 1995.

14 Styblo K, Meijer J, Sutherland I. The transmission of tubercle bacilli. Its trend in a human population. Bulletin International Union Tuberculosis 1969;42:5-104

15 Rieder HL. Methodological issues in the estimation of the tuberculosis problem from tuberculin surveys. Tuber Lung Dis 1995;76:114-21.

16 Servicio de Epidemiología. Indicadores de salud de la Región de Murcia: actualización 1996. Boletín Epidemiológico de Murcia 1996;17:25-32.

17 Navarro-Alonso JA, Hernando-Arizaleta L, Galvañ-Olivares $\mathrm{F}$, Calle-Urra JE. Infección tuberculosa en escolares de $1^{\circ}$ de EGB de la Región de Murcia (1985-1992). Aten Primaria 1993;12:573-6.

18 Ordobás-Gavín M. Encuesta de tuberculina en la Comunidad de Madrid. Madrid: Consejería de Sanidad y Servicios Sociales, 1995.

19 García-Rodríguez JF, De Juan-Prego, Rodríguez-Mayo M, Sesma-Sánchez P, González-Moraleja J. Epidemiologia de la tuberculosis en El Ferrol. Med Clin (Barc) 1995;104: $365-8$.

20 Castro I, Jiménez FJ, Rosales M, Domínguez V. Evolución de la incidencia de enfermedad tuberculosa en el área sanitaria de La Coruña. Rev Sanid Hig Publica 1994;68:52130.

21 Jansà JM, Villalbí JR. La salud de los inmigrantes y la atención primaria. Aten Primaria 1995;15:320-7.

22 Durán E Cabezos J, Ros M, Terre M, Zarzuela F, Bada JL. Tuberculosis en inmigrantes recién llegados a Barcelona. Med Clin (Barc) 1996;106:525-8.

23 Kasl S, Berkman L. Consequences of the experience of migration. Ann Rev Public Health 1983;4: 69-90.

24 Mohle-Boetani JC, Miller B, Halpern M, Trivedi A, Lessler $\mathrm{J}$, Solomon SL, et al. School-based screening for tuberculous infection. A cost-benefit analysis. $\mathscr{F} A M A$ 1995;274: 613-19.

25 Styblo K, Enarson DA. Epidemiology of tuberculosis in HIV prevalent countries. In: Styblo K. Epidemiology of tuberculosis. Selected papers. The Hague: Royal Netherlands Tuberculosis Association, 1991:116-36.

26 Raviglione MC, Snider DE, Kochi A. Global epidemiology of tuberculosis. Morbidity and mortality of a world-wide epidemic. $¥ A M A$ 1995;273:220-6. 